\title{
Science of consciousness: reflections on the Pandemic by COVID-19
}

\author{
Darco Osini $\mathbf{1}^{\mathbf{2}, \mathbf{3}}$ \\ (iD) Carlos Henrique Melo Reis ${ }^{4}$ \\ (iD) Marco Antônio Alves Azizi ${ }^{5}$ \\ (D) Jacqueline Fernandes do Nascimento ${ }^{6}$ \\ (iD) Nicolle dos Santos Moraes Nunes ${ }^{6}$ \\ (D) Janie Kelly Fernandes do Nascimento ${ }^{6}$
}

\begin{abstract}
1. Médico, PhD pela Universidade Federal do Rio de Janeiro, Rio de Janeiro, R], Brasil 2. Professor titular na Universidade Iguaçu - UNIG, Nova Iguaçu, RJ, Brasil 3. Professor titular na Universidade de Vassouras - UniV-RJ, Vassouras, RJ, Brasil. 4. Médico, Neurologista, Mestre pela Universidade Federal do Rio de Janeiro, Rio de Janeiro, RJ, Brasil 5. Médico, Professor titular da faculdade de medicina em Universidade Iguaçu - UNIG, RJ, Nova Iguaçu, RJ, Brasil. 6. Acadêmica de medicina na Universidade Iguaçu - UNIG, RJ, Nova Iguaçu, RJ, Brasil.
\end{abstract}

KEYWORDS: Science. Coronavirus Infections. Scientific Research and Technological Development.

Uncertainty around the unknown and fascination with the world as it is perceived have accompanied humans from the very start of their journey on this blue planet, in the adventure in search of grasping and understanding the unknown. Knowledge emerges as a result of the creation experience, driven by thought as the consequence of brains in rapid expansion and development. This is the major role of thought, to facilitate the dynamic and ongoing transition from unknown to known. As time passed, with new knowledge at their disposal, humans were inserted in history and culture that were the driving force behind new creations, new horizons'.
Amazing constructions were built through different types of thinking in an attempt to give meaning to the unknown and new. Initially, many answers were provided by their own experiences, which allowed them to build a set of thoughts from individual opinions, which then became common sense. However, creativity and common thinking were not sufficient to answer their various questions around the unknown².

Plato, in Greece, according to the western perspective of the history of humanity, proposed a method to distinguish knowledge from opinions. Episteme is a knowledge whose validity can be demonstrated, unlike an opinion (doxa), which is unfounded and 
easily disposable, subject to changes in time and without a set of rules of its own. This differentiation applies to the current time, due to the flood of opinions that seek authority in these bleak times. It is urgent, therefore, that we are able to differentiate knowledge from opinions ${ }^{3}$.

Opinions or beliefs are not devoid of value, because they belong to an individual's content, to their own heritage; they are true in the intimate sphere. However, to become true knowledge they must be justified by a set of validation rules ${ }^{4}$.

It is worth remembering other magnificent paths that are important for the enrichment of human experience, all necessary for human life: art, philosophy, spirituality, religion, or simply human experience ${ }^{5}$.

In a context of modern history, scientific thought is defined as the need for a system of verifiable and objectively controlled trials. There was an important addition to the Platonic concept with the presence of more efficient and effective controls. Therefore, considering this important difference, it is unthinkable to have science without philosophy! ${ }^{6}$

In 1620, with the Novum Organum, by Francis Bacon, a model was proposed for the experimental scientific method, which, based on observation, seeks to explain natural phenomena; thus, theories are derived from, related to, and supported by the phenomena observed. Science ceases to be a contemplation of reality and becomes transformative of reality, and research becomes the foundation for science ${ }^{7}$.

Scientific knowledge deals with observable problems that are subjected to various scientific methods, unlike other types of knowledge that address the major themes of human existence (religious thoughts), which are not the object of natural sciences ${ }^{8}$.

Therefore, science aims to pursuit knowledge that is verifiable and subject to the rules of the scientific method; those passionate about practicing it honestly look for questions, which can sometimes be accompanied by answers. Answers may come or not in our time, but this certainly will not stop us from formulating thoughts and theories around our intellectual restlessness. In science, truths are always temporary since they are subject to the principles of fallibility, relativity, and debatability; therefore, there is no pretension of absolute validities. Only that which is debatable can be debated. That which is not debatable is a dogma. If it is a dogma, it has nothing to do with science. Everything is debatable in science. Science proposes an open debate. According to Habermas, the truth is the pretense of validity; nothing is indefinitely valid ${ }^{9}$.

Therefore, the results of certain published publish papers cause us great concern given their disobedience of the scientific rigor rules, postulating hasty information on therapies recommended for COVID-19 patients, which are subsequently reviewed and withdrawn with justifications of methodological inaccuracies. In science, the instituted authorities are the method used for a particular purpose; reasoning and ethics. The only way to preserve this process is by applying the scientific method and, most importantly, believing in the critical review by our peers, because everything is debatable in science. All of us, when designing and analyzing a study, must follow the principles of impartiality, of cumulative increase of knowledge, and of the logical structure of investigations and results. Let us remember that the scientific method does not always lead us to meritorious and reliable results - although it is the best path to be taken. We emphasize the hard work of some scientists in combating the improper use of information on COVID-19. "When science is lost, reason goes with it; when it is crushed, nothing else makes sense"10.

\section{Conflict of interest}

There is no potential conflict of interest relevant to this article.

\section{Author's Contribution}

All authors contributed equally to this study. 


\section{REFERENCES}

1. Ioannidis JPA. Coronavirus disease 2019: the harms of exaggerated information and non-evidence-based measures. Eur J Clin Invest. 2020;50(4):e13222.

2. Alfano V, Ercolano S. The efficacy of lockdown against COVID19: a cross-country panel analysis. Appl Health Econ Health Policy. 2020;18(4):509-17.

3. Malecki K, Keating JA, Safdar N. Crisis communication and public perception of COVID-19 risk in the era of social media. Clin Infect Dis. 2020; ciaa758. doi: 10.1093/cid/ciaa758.

4. Woodside AG. Interventions as experiments: connecting the dots in forecasting and overcoming pandemics, global warming, corruption, civil rights violations, misogyny, income inequality, and guns. | Bus Res. 2020;117:212-8

5. Tarazona-Santabalbina FJ, Martínez-Velilla N, Vidán MT, García-Navarro
JA. COVID-19, older adults and ageism: mistakes that should never happen again. Rev Esp Geriatr Gerontol. 2020;55(4):191-2.

6. Wu X. Materialism and dialectics of epidemic prevention and control: only by respecting science can we do more with less. Zhonghua Wei Zhong Bing ji Jiu Yi Xue. 2020;32(3):259-60.

7. Lippi G, Simundic AM, Plebani M. Potential preanalytical and analytical vulnerabilities in the laboratory diagnosis of coronavirus disease 2019 (COVID-19). Clin Chem Lab Med. 2020;58(7):1070-6.

8. Data error in viewpoint on COVID-19 in Italy. JAMA. 2020;323(16):1619.

9. Ellis R, Hay-David AGC, Brennan PA. Operating during the COVID19 pandemic: how to reduce medical error. Br J Oral Maxillofac Surg. 2020;58(5):577-80.

10. Gandhi TK, Singh H. Reducing the risk of diagnostic error in the COVID-19 era. J Hosp Med. 2020;15(6):363-6. 